\title{
Microparticles from Wheat-Gluten Proteins Soluble in Ethanol by Nanoprecipitation: Preparation, Characterization, and Their Study as a Prolonged-Release Fertilizer
}

\author{
Carlos G. Barreras-Urbina $\left(\mathbb{D},{ }^{1}\right.$ Francisco Rodríguez-Félix $\left(\mathbb{D},{ }^{1}\right.$ \\ Guadalupe A. López-Ahumada ${ }^{D},{ }^{1}$ Silvia E. Burruel-Ibarra, ${ }^{2}$ José A. Tapia-Hernández, ${ }^{1}$ \\ Daniela D. Castro-Enríquez $\mathbb{D}^{1}{ }^{1}$ and Edgar O. Rueda-Puente ${ }^{3}$ \\ ${ }^{1}$ Departamento de Investigación y Posgrado en Alimentos (DIPA), Universidad de Sonora, Hermosillo C.P. 83000, Mexico \\ ${ }^{2}$ Departamento de Investigación en Polímeros y Materiales (DIPM), Universidad de Sonora, Hermosillo C.P. 83000, Mexico \\ ${ }^{3}$ Departamento de Agricultura y Ganadería, Universidad de Sonora, Hermosillo C.P. 83000, Mexico \\ Correspondence should be addressed to Francisco Rodríguez-Félix; rodriguez_felix_fco@hotmail.com
}

Received 18 May 2018; Revised 7 August 2018; Accepted 27 August 2018; Published 11 October 2018

Academic Editor: Dirk Kuckling

Copyright (c) 2018 Carlos G. Barreras-Urbina et al. This is an open access article distributed under the Creative Commons Attribution License, which permits unrestricted use, distribution, and reproduction in any medium, provided the original work is properly cited.

\begin{abstract}
At present, the development of natural polymeric microparticles is carried out to obtain release systems. Prolonged-release systems are a potential solution to avoid nitrogen $(\mathrm{N})$ losses in agricultural fields. The aim of this study was to develop microspheres from wheat-gluten proteins soluble in ethanol $70 \%(\mathrm{v} / \mathrm{v})$, to ascertain their characterization, and to study their potential application in agricultural fields. Soluble-protein extraction was performed with $1600 \mathrm{~mL}$ of ethanol $70 \%(v / v)$. Likewise, ethanolic solutions with protein concentrations of $0.5 \%, 1 \%$, and $2 \%(w / v)$ are classified as non-Newtonian fluids with pseudoplastic behavior. Using the nanoprecipitation method, it was possible to develop urea-loaded microspheres with a diameter ranging from $900 \mathrm{~nm}-1.7 \mu \mathrm{m}$. The Fourier transform infrared spectroscopy (FTIR) test exhibited interaction through hydrogen bonds between carbonyls and amino groups from the urea and proteins. Also, the thermogravimetric analysis (TGA) test demonstrated thermal stability at $130^{\circ} \mathrm{C}$. The release experiment showed that the microspheres achieved equilibrium when $88 \%$ of the urea was released. Finally, according to the empirical model of Ritger and Peppas, urea release is carried out through Fickian diffusion. We conclude that the microspheres could be applied in the fields and with this improve agricultural practices. Also, they could reduce the potential environmental pollution and developing a sustainable agriculture.
\end{abstract}

\section{Introduction}

In recent years, the world population has increased, and also, its food requirement. Agriculture has been carried out since the early days of humans and comprises a primary food source for the latter. Therefore, better agronomic practices are required to meet the needs of the world population $[1,2]$. At present, new technologies are studied for possible application in agri-food industries in order to achieve improvements in safety and health and to obtain better quality products, as well as to increase the yield of products from agricultural fields [2].
Microtechnology is a science that provides favorable qualities for application in this industry, and it has been implemented in other areas. Additionally, it provides the necessary tools that can be applied as an alternative for control and food production $[3,4]$. The advantage lies in that microparticles can encapsulate active compounds that help to improve agricultural products. The nanoprecipitation method is easy, fast, and one with a low energy expenditure, and it has good results for the encapsulation of active compounds [5]. The technique involves the formation of an organic phase composed of a polymer, an active compound, and the suitable solvent for both. This phase is added to an 
antisolvent phase, which gives rise to solvent displacement through the action of the compound's polarity. The process involves the nucleation process and concludes with the formation of nano- or microparticles $[6,7]$.

In recent years, synthetic and natural polymers have been employed for the preparation of nano- and microparticles [8]. Proteins are natural polymers utilized for the preparation of materials that are biodegradable and biocompatible [9]. Wheat gluten is rich in gliadins and glutenins. Gliadins are monomeric proteins with a molecular weight within the range of $30,000-80,000 \mathrm{Da}$, and they are extracted from wheat gluten due to their solubility in alcoholic solutions. On the other hand, glutenins are polymeric proteins with a molecular weight falling with the range of $80,000 \mathrm{Da}$ to more 10 million $\mathrm{Da}$, and they are soluble in acidic solutions [10-12]. Both proteins have been investigated for their use in the preparation of materials on the nano- and microscale, as well as in controlled- and prolonged-release systems, because of its application in agricultural fields and the food industry $[13,14]$.

The application of pesticides and fertilizers is a necessary and common practice in agricultural fields. Fertilizers are rich in nutrients such as nitrogen $(\mathrm{N})$, potassium $(\mathrm{K})$, and phosphorus (P). Urea is one of the main fertilizers utilized worldwide because it is necessary for plant growth, due to its high $\mathrm{N}$ content (46\%). Usually, urea is lost by means of the leaching, volatilization, and denitrification processes. This leads to obtaining low yields and low-quality products and could also produce environmental pollution $[15,16]$. Therefore, nanoand micromaterials could be applied as the prolonged- or controlled-release systems of fertilizers in order to improve agricultural crops, increase product quality and yield, and decrease environmental pollution [13]. The Agrifood and Fisheries Information Service (SIAP, its Spanish-language acronym) reports that Mexico produces about 3,710,706 tons of wheat per year, and $44 \%$ is produced in the northern state of Sonora, especially wheat of the species Triticum durum (SIAP, 2015 (https://www.gob.mx/siap)).

The aim of this work was the preparation and characterization of microparticles from Wheat-Gluten Proteins Soluble in Ethanol (WGPSE) (mainly gliadins). These microparticles were loaded with urea, and we conducted its prolongedrelease study. The latter was performed to obtain information to determine their potential use as urea prolonged-release systems and to attempt to apply better agronomic practices.

\section{Materials and Methods}

The materials and methods used in this study are wheat grain (Triticum durum) variety Júpare (2008-2009), ethanol (Sigma-Aldrich), 1-propanol (Sigma-Aldrich), acetone (Sigma-Aldrich), acetic acid (Sigma-Aldrich), urea (Fermont), the surfactant Poloxamer 188 (Sigma-Aldrich), dialysistubing cellulose membranes with a molecular weight cut-off of $14,000 \mathrm{Da}$ (Sigma-Aldrich), and the Berthelot method (Randox kit).

2.1. Production of Wheat Flour and Obtaining Wheat Gluten. Wheat grain was conditioned with $16.5 \%$ moisture, and the flour was made using a mill (Brabender Quadrumat Senior), according to the 26-10 method (AACC, 2000). Wheat gluten was obtained when the flour was washed with distilled water several times in order to remove the starch. Yields of wheat flour and gluten were determined.

2.2. Determination of Protein Content. The analyses were determined through the Nitrogen/Protein Analyzer (LECO, Model NP528) using a conversion factor of 5.7.

2.3. Determination of Moisture Content. Moisture content was obtained using the 925.10 method (AOAC, 1995).

2.4. Percentage of Solubility of Ethanol-Soluble Proteins from Wheat Gluten. Percentage of solubility was calculated using the methods reported by Kayserilioğlu et al. [17] and Shukry et al. [18]. In this experiment, $1 \mathrm{~g}$ of material previously extracted for this test was added to $20 \mathrm{~mL}$ of the solvent at different concentrations (ethanol/water mixture of 50, 60, $70,80,90$, and $100 \%(v / v))$. The suspensions were centrifuged at $8300 \mathrm{~g}$ during $20 \mathrm{~min}$ (Hermle Labortechnik, Model $\mathrm{z} 36 \mathrm{HK}$ ), and the insoluble fraction was isolated, freeze-dried, and weighed.

2.5. $\mathrm{pH}$ Measurements. The $\mathrm{pH}$ value of the solutions was determined using a pH meter HI-2550 (Hanna Instruments).

2.6. Standardization of the Extraction of Soluble Proteins in Ethanol from Wheat Gluten. Proteins were extracted from wheat gluten using the method reported by Ang et al. [19] with some modifications in solvent volumes. $100 \mathrm{~g}$ of gluten was added to different volumes of ethanol $70 \%(v / v)$ (Table 1).

The mixture was subjected to $12 \mathrm{~h}$ of propeller stirrer (Yamato Scientific, Model LT400D) and centrifuged at $3470 \mathrm{~g}$ for $15 \mathrm{~min}$. The supernatant was recovered and purified by dialysis process. The soluble fraction was freezedried (LABCONCO, Kansas City, MO, USA) and weighed.

2.7. Rheological Characterization. Soluble-fraction solutions with concentrations of $0.5 \%, 1 \%$, and $2 \%$ were prepared in ethanol $70 \%(v / v)$. Rheological measurements were carried out under the conditions reported by Sun et al. [20] utilizing a rheometer (Anton Paar Model MCR102) with a concentriccylinder system. The shear rate employed ranged from $0.1 \mathrm{~s}^{-1}$ to $1000 \mathrm{~s}^{-1}$ at $25^{\circ} \mathrm{C}$.

2.8. Statistical Analysis. Descriptive statistics were applied to the data obtained from this experiment, such as averages and standard deviations (SD). A Tukey mean-difference test was performed with a significance level of $p>0.05$.

2.9. Development of Microparticles of Ethanol-Soluble Proteins from Urea-Loaded Wheat Gluten. The microparticles were prepared by the nanoprecipitation method reported by Fessi et al. [21] with some modifications. The organic phase was made with ethanol $70 \%(v / v)$, mixing soluble proteins and urea and using concentrations of $1 \%(w / v)$ and $0.5 \%(w / v)$, respectively. The aqueous phase was prepared with distilled water and $0.05 \%(w / v)$ of Poloxamer 188 . The organic phase was injected drop-wise into the aqueous phase 
TABLE 1: Standardization of the extraction of proteins soluble in ethanol $70 \%(v / v)$ from wheat gluten.

\begin{tabular}{lcc}
\hline $\begin{array}{l}\text { Wheat gluten } \\
\text { weight }(\mathrm{g})\end{array}$ & $\begin{array}{c}\text { Ethanol } 70 \% \\
(v / v)(\mathrm{mL})\end{array}$ & $\begin{array}{c}\text { Amount of proteins } \\
\text { extracted }(\mathrm{g})\end{array}$ \\
\hline \multirow{4}{*}{100} & 800 & 20.97 \\
& 1000 & 18.79 \\
& 1600 & 34.96 \\
1800 & 32.84 \\
2000 & 21.25 \\
\hline
\end{tabular}

utilizing a peristaltic pump (Kd Scientific) with a flow rate of $5 \mathrm{~mL} \mathrm{~h}^{-1}$ under a propeller stirrer (Yamato Scientific, Model LT400D). The resulting suspension was lyophilized (LABCONCO).

2.10. Scanning Electron Microscopy (SEM). Micrographs of WGPSE microparticles were obtained utilizing JEOL Model $5410 \mathrm{LV}$ equipment operated at $15 \mathrm{kV}$, and the samples were gold-sputtered prior to the examination.

2.11. Attenuated Total Reflectance-Fourier Transform Infrared Spectroscopy (ATR-FTIR). The samples were analyzed using a Perkin-Elmer two-spectrum equipment employing FTIR equipment with a diamond ATR attachment.

2.12. Thermogravimetric Analysis (TGA). Samples of $3 \mathrm{mg}$ were weighed and analyzed in Perkin-Elmer TGA equipment (Model Pyris 1) employing a nitrogen atmosphere, with a flow rate of $10^{\circ} \mathrm{C}$ per minute until reaching $600^{\circ} \mathrm{C}$.

2.13. Urea-Release Experiment. The spheres were dispersed in a glass with $1 \mathrm{~L}$ of deionized water at $25^{\circ} \mathrm{C}$ under stirring at $250 \mathrm{rpm}$ utilizing a magnetic stirrer (IKA C-MAG HS7). The urea released was determined at $2,4,6,8,10,12,14$, and 16 hours. Ten milliliters of sample was removed from the deionized water and replaced with $10 \mathrm{~mL}$ of deionized water in order to maintain $1 \mathrm{~L}$ in the aqueous medium, according to the methodology reported by Gulfam et al. [22]. The urea concentration released into the aqueous medium was determined through the Berthelot method according to the Randox kit, employing UV-vis spectrophotometry using an equipment VARIAN model Cary 50. Reagent 1 (R1) was prepared adding R1a, which is formed by the urease enzyme, and R1b which is formed by the phosphate buffer (sodium salicylate, sodium nitroprusside, and EDTA). Then, three vials were prepared; (1) $1000 \mu \mathrm{L}$ of R1 was added to form the reagent blank, (2) $10 \mu \mathrm{L}$ of the standard and $1000 \mu \mathrm{L}$ of the R1 were added and mixed to form the standard sample, and (3) $10 \mu \mathrm{L}$ of the sample and $1000 \mu \mathrm{L}$ of $\mathrm{R} 1$ were added and mixed. Then, the three samples were incubated during 5 minutes at $25^{\circ} \mathrm{C}$. After, $200 \mu \mathrm{L}$ of sodium hypochlorite (R2) was added to each vial. The three samples were mixed separately and incubated during $10 \mathrm{~min}$ at $25^{\circ} \mathrm{C}$. Finally, the absorbance of the samples was measured at $600 \mathrm{~nm}$. Berthelot method is based on the reaction of aqueous urea in the presence of the urease enzyme to transform into $2 \mathrm{NH}_{3}+\mathrm{CO}_{2}$. After, the salicylate and hypochlorite reagents react with the ammonium ions and transform the sample in a green complex named 2,2-dicarboxylindophenol.

\section{Results and Discussion}

3.1. Production of Wheat Flour and the Wheat Gluten Obtained. The yield of wheat flour was $54 \%$ and the rest was wheat bran, and the wheat-gluten yield obtained was 9\% (on a dry matter (DM) basis). Barak et al. [23] reported a wheat-flour yield of $65 \%$, and these authors obtained wheat gluten with a range of $7.92-10 \%$ of protein, and wheat flour was obtained from four different varieties of wheat. The difference between both yields could be due to that the raw material for the experiments was different; this means that $11 \%$ less wheat flour was utilized for the combination of different wheat varieties of bread wheat and wheat pasta, while a wheat-flour yield of $54 \%$ was from wheat pasta only, which could be a factor in terms of the reduced yield in comparison with that of bread wheat. Moreover, values of wheat-gluten protein were similar between both studies.

3.2. Percentages of Solubility of Wheat-Gluten Proteins Soluble in Ethanol (WGPSE). Table 2 presents the concentrations of ethanol tested and the $\mathrm{pH}$ of each. The high solubility in ethanol $70 \%(v / v)$ in comparison with that of the other concentrations is attributed to hydrogen bonds between the solvent and the protein. Soluble proteins are unfolded and possess the amino groups available for the interaction through hydrogen bonds. The isoelectric point of these proteins is around $\mathrm{pH} 7.8$, considering mainly gliadins, and the remainder, low molecular weight (LMW) glutenins. The $\mathrm{pH}$ value of ethanol $70 \%(v / v)$ was 5.88 in comparison with the other $\mathrm{pH}$ values of the concentrations. It is remarkable that another factor that exerts an influence on the solution of ethanol $70 \%(v / v)$ in order for it to present over $90 \%$ solubility is that the $\mathrm{pH}$ value is far from the $\mathrm{pH}$ value for considering the isoelectric point. Joye et al. [24] report that the isoelectric point of gliadin protein is $\mathrm{pH} \approx 7.8$. Proteins do not reach the neutral charge of their amino acids; thus, they cannot reach their isoelectric point. This causes the protein to lose solubility due to the conformation that it adopts, in which its $\mathrm{R}$ side chains are accommodated in such a way that the solvent can interact with side chains that are as polar, such as ethanol $70 \%(v / v)$.

This, in turn, causes a variation in its $\mathrm{pH}$, which is reflected in its remoteness from its isoelectric point; therefore, its low solubility in the solvent.

3.3. Process of Obtaining a WGPSE. The best amount of ethanol at $70 \%(v / v)$ to obtain WGPSE was $1600 \mathrm{~mL}$, obtaining $34.96 \mathrm{~g}$ of proteins (Table 1). These results demonstrate that the volume at which ethanol $70 \%(v / v)$ can extract the greatest amount of gliadins and LMW glutenins from wheat gluten is by employing $1600 \mathrm{~mL}$. This can be explained because the amount of ethanol is sufficient to interact with the majority of the gliadins and LMW glutenins, exhibiting easy interaction between the solvent and the protein structure. The ethanol-soluble protein fraction is composed mainly of LMW gliadins and glutenins $(20 \mathrm{kDa}-45 \mathrm{kDa})$ 
TABLE 2: Effect of the ethanol concentration on the solubility and $\mathrm{pH}$ of WGPSE solutions.

\begin{tabular}{lcc}
\hline Ethanol concentration (\%) & Solubility (\%) & $\mathrm{pH}$ \\
\hline 50 & 90.60 & 6.22 \\
60 & 95.12 & 6.11 \\
70 & 96.35 & 5.88 \\
80 & 55.82 & 6.19 \\
90 & 7.07 & 6.05 \\
100 & 23.63 & 6.00 \\
\hline
\end{tabular}

[25]. The appropriate volume for best extraction of soluble proteins in ethanol was $1.6 \mathrm{~L}$. However, as the ethanol volume increased, the yield decreased. This can be attributed to that ethanol interacts with all of the gliadins present in the solution. While the ethanol volume was increasing, the solvent began to separate LMW glutenins from the gliadins, i.e., excess of ethanol causes a dissociation of LMW glutenins, which are very similar to the gliadins, the reason why the yield of soluble proteins in ethanol decreases (Figure 1). Gliadins and glutenins are proteins classified as prolamins, which interact with each other because of the ease of their amino acids to form hydrogen bonding and disulfide-bond interactions $[10,25,26]$. They mainly contain the amino acids glutamine, proline, methionine, isoleucine, cysteine, serine, phenylalanine, and tyrosine $[10,25]$.

Wheat-gluten protein content was $77 \%$ (DM basis), and moisture content was $4.72 \%$. The yield obtained was 34.92\% (DM basis), with a protein content of $85 \%$ (DM basis) and a moisture content of 6\%. Fajardo et al. [27] extracted gliadins from commercial wheat gluten, obtaining a gliadin-rich fraction equivalent to $15 \%$, while this experiment demonstrates a higher protein yield due the quality of the extraction and focusing mainly on proteins soluble in ethanol, these mainly gliadins and LMW glutenins. The method was standardized, and this experiment revealed very good results, obtaining more than $34 \%$ of the gliadin-rich fraction.

3.4. Rheological Characterization. Figure 2 illustrates the effect of shear rate $\dot{\gamma}$ on shear stress $\tau$ for low concentrations at $25^{\circ} \mathrm{C}$. Protein solutions are classified as non-Newtonian fluid because they do not possess directly proportional behavior between shear stress and shear rate. Protein solutions do not follow Newton's law of viscosity.

The standard deviation (SD) of the average of each point of the experiment (protein solutions at $0.5 \%, 1 \%$, and $2 \%$ ) presents values near zero. Protein solutions exhibit apparent linear behavior with a shear rate ranging from $0 \mathrm{~s}^{-1}$ to $200 \mathrm{~s}^{-1}$. Finally, experimental solutions with low concentrations of WGPSE comprise non-Newtonian fluid. At this point, protein solutions could entertain shear-thickening behavior.

Figure 3 depicts the effect of shear rate on viscosity for the three WGPSE concentrations at $25^{\circ} \mathrm{C}$, where it can be observed that the fluid is non-Newtonian, as in Figure 2 in terms of shear stress. In this case, when the shear rate increased, the apparent viscosity also increased. This is attributed to the energy-dissipation increase with the shear rate, resulting in shear-thickening (dilatant) behavior [28].
This result demonstrates that the protein solutions will continue to increase in viscosity with the nanoprecipitation technique's shear rate. Particle diameter could be affected by the type of fluid applied to the nanoprecipitation process, and it is possible that a non-Newtonian fluid with shearthickening behavior could develop particles with a size ranging in micrometers, because the viscosity will increase the nucleation rate.

Power law and Pearson correlation coefficient were applied to the results obtained from the solutions in order to confirm that protein solutions are non-Newtonian fluids and that they possess shear-thickening behavior, considering the flow-index value obtained and the $R^{2}$ value. Table 3 presents different concentrations of WGPSE and flow-index values. The flow index is above 1 at the three concentrations, implying that the protein solutions are non-Newtonian fluids with shear-thickening behavior. Concentrations of the protein solutions do not present significant differences in flowindex values. The solution with a concentration of $1 \%(w / v)$ is the suitable solution for obtaining a better yield in comparison with a protein solution of $0.5 \%(w / v)$ and of $2 \%(w / v)$.

Sun et al. [29] report that gliadin solutions in propanol $50 \%(v / v)$ are classified as Newtonian fluids, but gliadin solutions possess shear-thinning behavior (pseudoplastic behavior) when they maintain a $\mathrm{pH}$ of $2.0-8$. Sun et al. [20] showed similar results to those of their later research, where the authors classified gliadin solutions as Newtonian fluids at different concentrations of the protein. The results obtained from this research reveal that protein solutions with low concentrations are non-Newtonian fluids with shearthickening behavior. When it is necessary to obtain particles with diameters in micrometers, it is recommendable to apply solutions with shear-thickening behavior. On the other hand, it is not recommendable to use this type of solution to obtain nano- or microscale particles because the increase of viscosity results in nonhomogeneous particles. The results of Sun et al. $[20,29]$ are not similar to ours; first of all, proteins in our research were extracted from wheat gluten obtained from Triticum durum wheat grain, and it is important to consider the genetic differences between Triticum durum and Triticum aestivum. It is also important to bear in mind that, in the present study, proteins soluble in ethanol were tested. In addition, the solvent used for this experiment resulted as the best solvent in comparison with the others; propanol and ethanol yield different results in terms of protein solubility. In this experiment, ethanol was the best solvent for application in the nanoprecipitation process because it tends to form protein solutions, thus taking advantage of its high capacity to dissolve them, which is necessary to obtain particles through the nanoprecipitation technique.

3.5. Scanning Electron Microscopy (SEM) of Urea-Loaded Wheat-Gluten Proteins Soluble with Ethanol (WGPSE) Microparticles and WGPSE without Urea. Figure 4 illustrates WGPSE microparticles; (a) without urea and (b) loaded with urea. Particle size ranges from $900 \mathrm{~nm}-1.7 \mu \mathrm{m}$ with apparent spherical morphology; although agglomeration is present, but particle form and size are distinguishable, forming chains. Particle size between loaded and nonloaded microparticles 


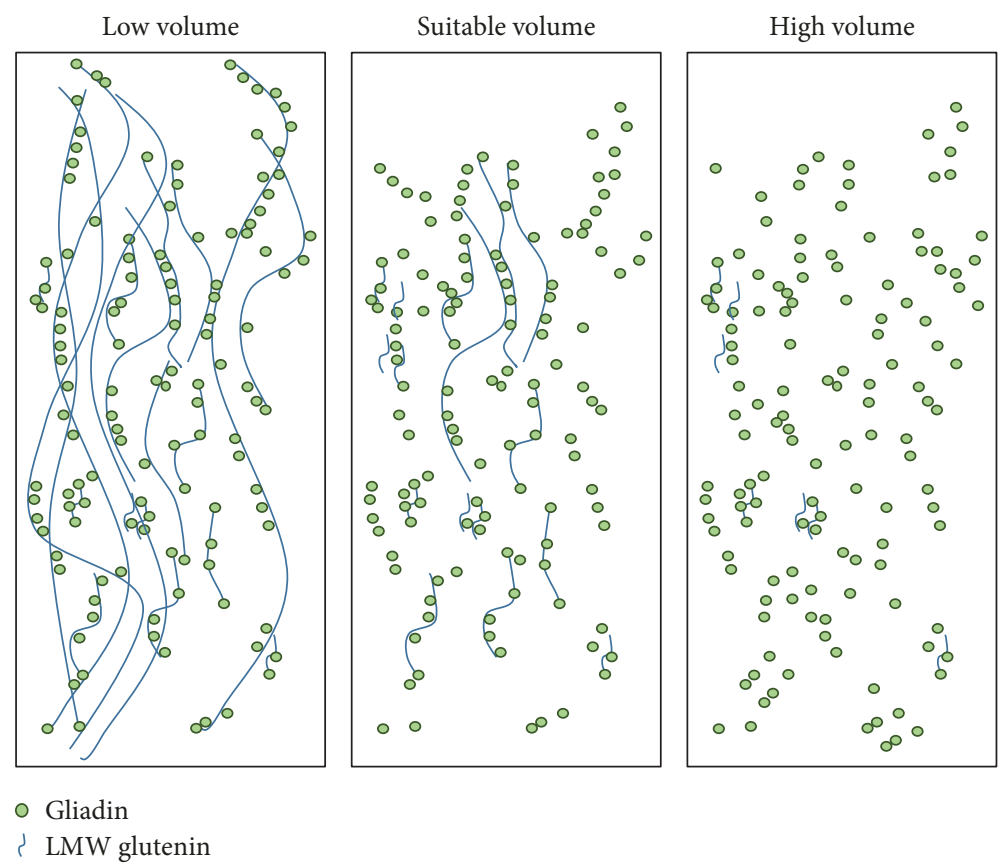

FIGURE 1: Gliadin and glutenin behavior in different volume of ethanol 70\% $(v / v)$.

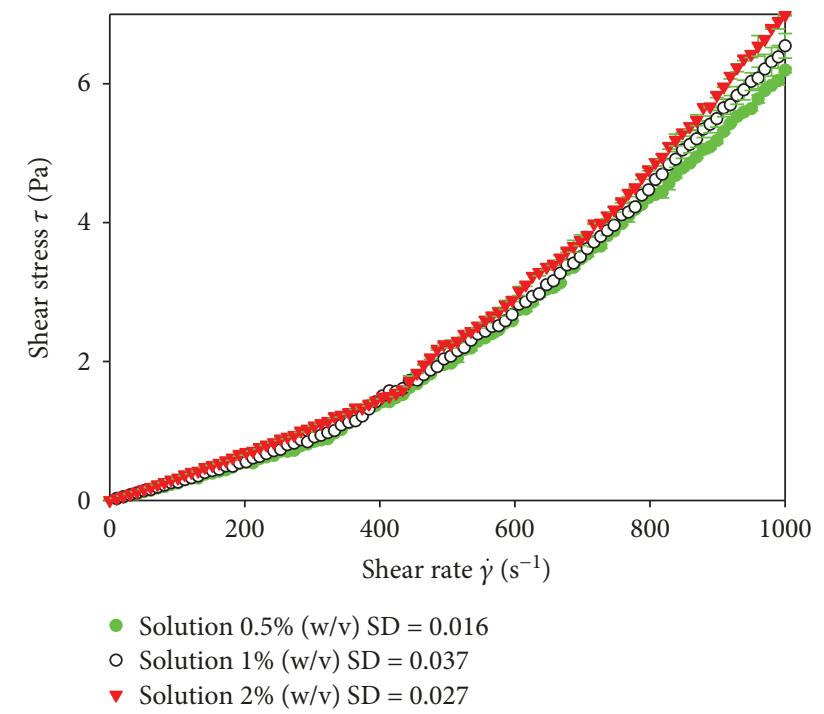

Figure 2: Effect of shear rate $\dot{\gamma}$ on shear stress $\tau$ for low concentrations of wheat-gluten proteins soluble in ethanol (WGPSE) at $25^{\circ} \mathrm{C}$.

does not have significant variation, and the urea is dispersed in the polymeric matrix; thus, it is not present in the micrographs. On the other hand, the stabilizer confers stability on the particle system between the polymeric matrix and the aqueous phase, but it was not $100 \%$ effective in this experiment. Therefore, there is agglomeration of the microparticles. On the other hand, the agglomeration afforded by noncovalent bonds does not exert an effect on the release, because the difference between the superficial area of particle in chain form and individual particles is not

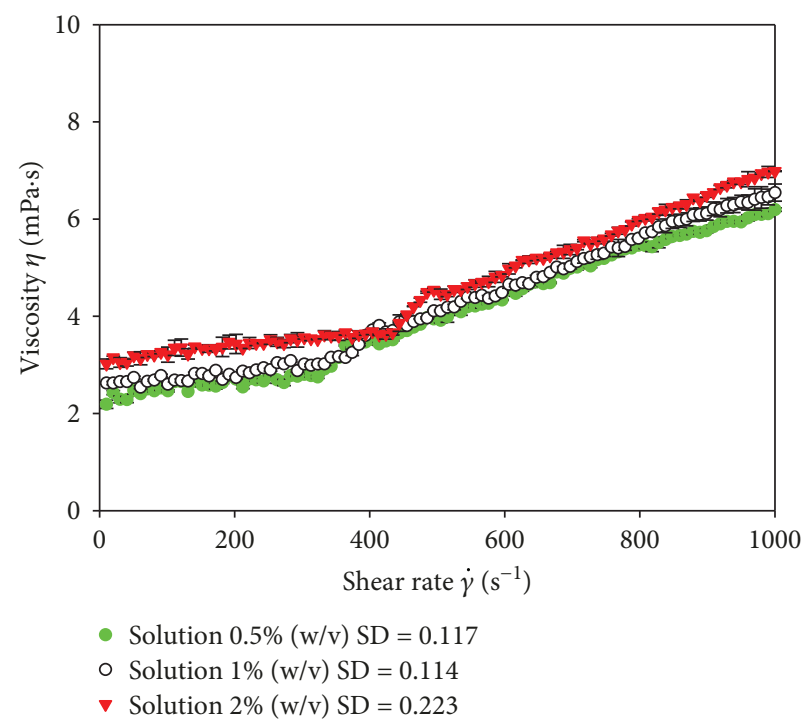

FIGURE 3: Effect of shear rate on viscosity for the three solutions of WGPSE at different concentrations, at $25^{\circ} \mathrm{C}$.

significantly affected. This information is in agreement with that mentioned by Bruinink et al. [30]. These results are convenient for their potential application because it is important to maintain slow release of this fertilizer.

Davidov-Pardo et al. [31] reported gliadin particles with spherical morphology with a diameter of $200 \mathrm{~nm}$, and agglomeration is present but the particles are distinguishable. Hence, the results are similar in both studies; the important difference lies in particle diameter, which was provided by the rheological characteristics of the protein solutions subjected to the nanoprecipitation process. 
TABLE 3: Effect of the concentration of wheat-gluten proteins soluble in ethanol (WGPSE) on the flow index $(n)$ calculated by power law and Pearson correlation coefficient values.

\begin{tabular}{lcc}
\hline WGPSE concentration (\%) & $N$ & $R^{2}$ \\
\hline 0.5 & $1.29 \pm 0.01^{* \mathrm{a}}$ & 0.987 \\
1 & $1.28 \pm 0.00^{\mathrm{a}}$ & 0.981 \\
2 & $1.16 \pm 0.11^{\mathrm{a}}$ & 0.973 \\
\hline
\end{tabular}

*Standard deviation (SD). Values with equal letters are not significantly different from each other.

3.6. Fourier Transform Infrared Spectroscopy (FTIR). Figure 5 presents the FTIR spectra for wheat flour, wheat gluten, and WGPSE (gliadins, mainly). The FTIR of the wheat flour presents a medium-intensity band at $3296 \mathrm{~cm}^{-1}$ that corresponds to the stretching of the hydroxyl groups in the amino acids of the wheat-flour proteins. Likewise, a medium-intensity band at $2932 \mathrm{~cm}^{-1}$ corresponds to the stretching of the group $\mathrm{CH}_{2}{ }^{-}$. Also, it presents a medium-intensity band at $1652 \mathrm{~cm}^{-1}$ and a weak-intensity band at $1535 \mathrm{~cm}^{-1}$; these latter bands correspond to the vibrational stretching of amide I $(\mathrm{C}=\mathrm{O})$ and the vibration frequency of amide II $(\mathrm{N}-\mathrm{H})$, respectively. Finally, there are strong-intensity bands at $1002 \mathrm{~cm}^{-1}, 1074 \mathrm{~cm}^{-1}$, and $1150 \mathrm{~cm}^{-1}$ due to the vibrations of the -C-O-C- bonds present in the starch. The bands observed from $600 \mathrm{~cm}^{-1}$ to $1150 \mathrm{~cm}^{-1}$ are characteristic of the starch and are also called starch fingerprints due to their furanose and pyranose rings. The spectroscopy of wheat gluten and gliadins demonstrates a medium-intensity band at $3296 \mathrm{~cm}^{-1}$ and a medium-intensity band at $2932 \mathrm{~cm}^{-1}$, and both bands were mentioned previously. Also present are the characteristic bands of amide I and amide II at $1655 \mathrm{~cm}^{-1}$ and $1536 \mathrm{~cm}^{-1}$, respectively. The wheat-gluten spectrum does not exhibit the characteristic bands that represent the presence of starch. Due to the obtaining of wheat gluten, the starch content is removed. The spectrum corresponding to gliadins reveals the absence of the starch's characteristic bands, meaning that the production and purification processes were effective. Castro-Enríquez et al. [14] reported the presence of the characteristic bands in commercial wheat gluten, which are similar to those found in this paper for durum wheat gluten.

Figure 6 presents the spectroscopy of (A) WGPSE (gliadins, mainly) and (B) WGPSE microparticles. WGPSE microparticles exhibit the bands of amide I and amide II. Likewise, we noted the band characteristic of the $\mathrm{OH}$ of the proteins. This spectroscopy demonstrates that gliadins do not have an alteration in their chemical structure after the nanoprecipitation process, due to that the latter is not an aggressive method and heat is not applied for the process to obtain nano- and microparticles. This means that the particles maintain the characteristic protein bands. The dominance of amide I bands shows that the protein maintains an alpha helix structure. This affirmation is in agreement with what was reported by Secundo and Guerrieri [32], where these authors mentioned the secondary structure of gliadins by FTIR spectrum.
Figure 7 depicts the FTIR spectra of urea, gliadin microparticles without urea, and urea-loaded gliadin microparticles. Figure 7 (a) presents the spectroscopy of urea, with a medium-intensity band at $3436 \mathrm{~cm}^{-1}$, which corresponds to the primary amine characteristic in the urea. Also, it presents a medium-intensity band at $1678 \mathrm{~cm}^{-1}$, which corresponds to the carbonyl group $(\mathrm{C}=\mathrm{O})$. Figure $7(\mathrm{~b})$ demonstrates the spectroscopy of WGPSE microparticles without urea, revealing a low-intensity band at $3302 \mathrm{~cm}^{-1}$ and a mediumintensity band at $2880 \mathrm{~cm}^{-1}$, corresponding to the stretching of the $\mathrm{O}-\mathrm{H}$ group and the stretching of the $\mathrm{C}-\mathrm{H}$, respectively.

Figure 7(c) depicts the spectroscopy of WGPSE microparticles loaded with urea, with this spectroscopy presenting the strong-intensity band characteristic of the primary amine at $3436 \mathrm{~cm}^{-1}$. In addition, it presents the strong-intensity band of the carbonyl group $(\mathrm{C}=\mathrm{O})$ found in urea and in WGPSE microparticles without urea. These results show that there is strong interaction afforded by the hydrogen bonds between the urea loaded and the gliadins (polymeric matrix), the latter performed by the amine group of the gliadins and the carbonyl group in the urea. This interaction is demonstrated by a shift-in-position of the carbonyl band to $52 \mathrm{~cm}^{-1}$ for urea and by a shift-in-position for gliadins to $29 \mathrm{~cm}^{-1}$.

3.7. Thermogravimetric Analysis (TGA). Figure 8 shows the TGA curves, and Table 4 indicates the weight loss percentage at different temperatures of WGPSE microparticles loaded with urea, WGPSE microparticles without urea, WGPSE (gliadins, mainly), and urea. Urea exhibits stability at around $145^{\circ} \mathrm{C}$ and, at this point, begins its degradation, losing around $75 \%$ of its total weight when $228^{\circ} \mathrm{C}$ is reached, subsequently completing its degradation at $477^{\circ} \mathrm{C}$. WGPSE microparticles show a weight loss of $6 \%$ when the temperature is around $100^{\circ} \mathrm{C}$; this loss is probably moisture. Also, from $100^{\circ} \mathrm{C}$ to $218^{\circ} \mathrm{C}$, they exhibit a weight loss of around $8 \%$ of total weight, while after that, they present their most important weight loss, from $218^{\circ} \mathrm{C}$ to $410^{\circ} \mathrm{C}$, when they lose $78 \%$ of weight, finally completing their degradation on reaching $800^{\circ} \mathrm{C}$. WGPSE microparticles without urea show an initial weight loss of about $2 \%$ when they are heated at $100^{\circ} \mathrm{C}$, which is probably moisture. When they reach $174^{\circ} \mathrm{C}$ to $445^{\circ} \mathrm{C}$, they present a weight loss of $80 \%$, while on reaching $800^{\circ} \mathrm{C}$, their total degradation is complete. These results demonstrate that microparticles without urea present stability at $174^{\circ} \mathrm{C}$, while WGPSE microparticles loaded with urea present a weight loss of $2 \%$ when reaching $130^{\circ} \mathrm{C}$, which is probably moisture. Finally, from $130^{\circ} \mathrm{C}$ to $800^{\circ} \mathrm{C}$, their degradation is total. These results reveal that WGPSE microparticles loaded with urea can be used as release systems with high temperatures because they are stable at $130^{\circ} \mathrm{C}$.

3.8. Prolonged Release of Urea from WGPSE Microparticles. Figure 9 presents the results of the release of urea from WGPSE microparticles. WGPSE microparticles released around $50 \%$ of the urea during the first hour. This is attributed to that urea is found on the surface of the microparticles, which is in contact with the aqueous medium. Also, urea is present that is forming part of the polymeric matrix, due to 


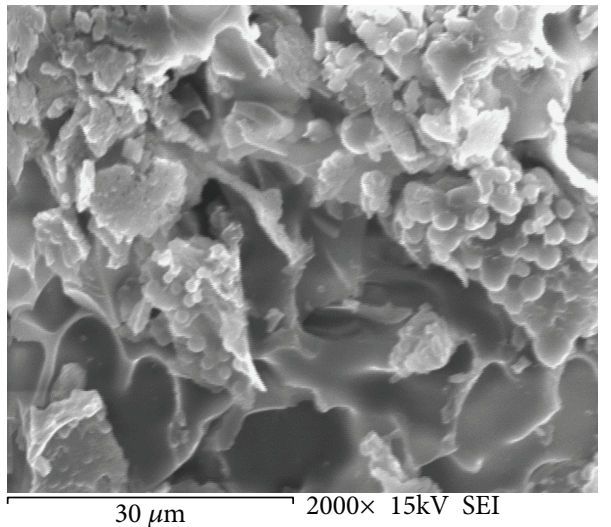

(a)

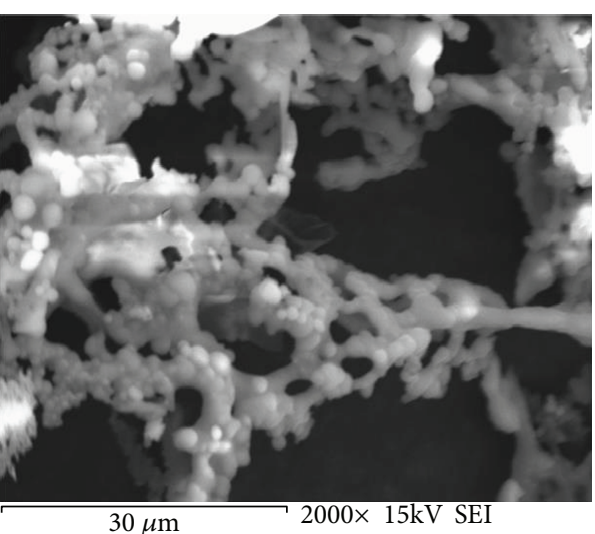

(b)

FIGURE 4: Scanning electron microscopy (SEM) micrographs of wheat-gluten proteins soluble in ethanol (WGPSE) microparticles with 2000x magnification; (a) without urea and (b) loaded with urea.

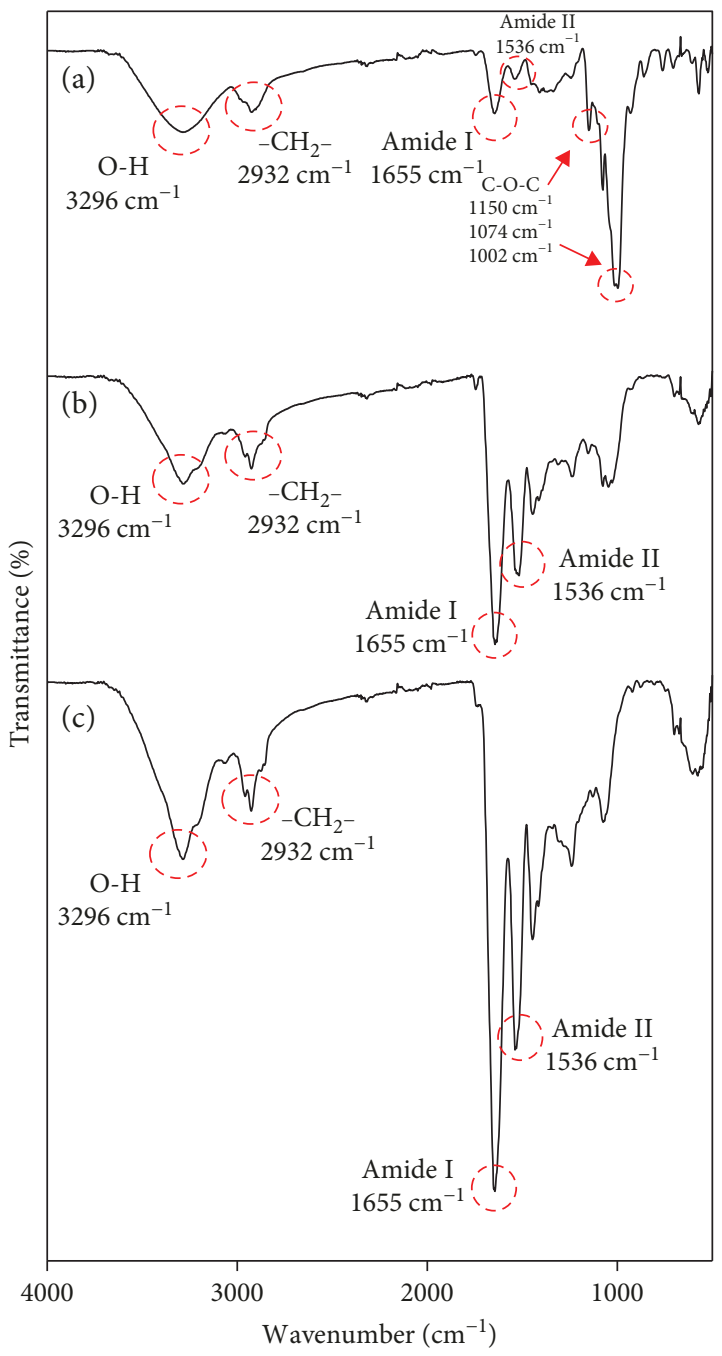

FIGURE 5: Fourier transform infrared (FTIR) spectrum of (a) wheat flour, (b) wheat gluten, and (c) wheat-gluten proteins soluble in ethanol (WGPSE) (gliadins, mainly).

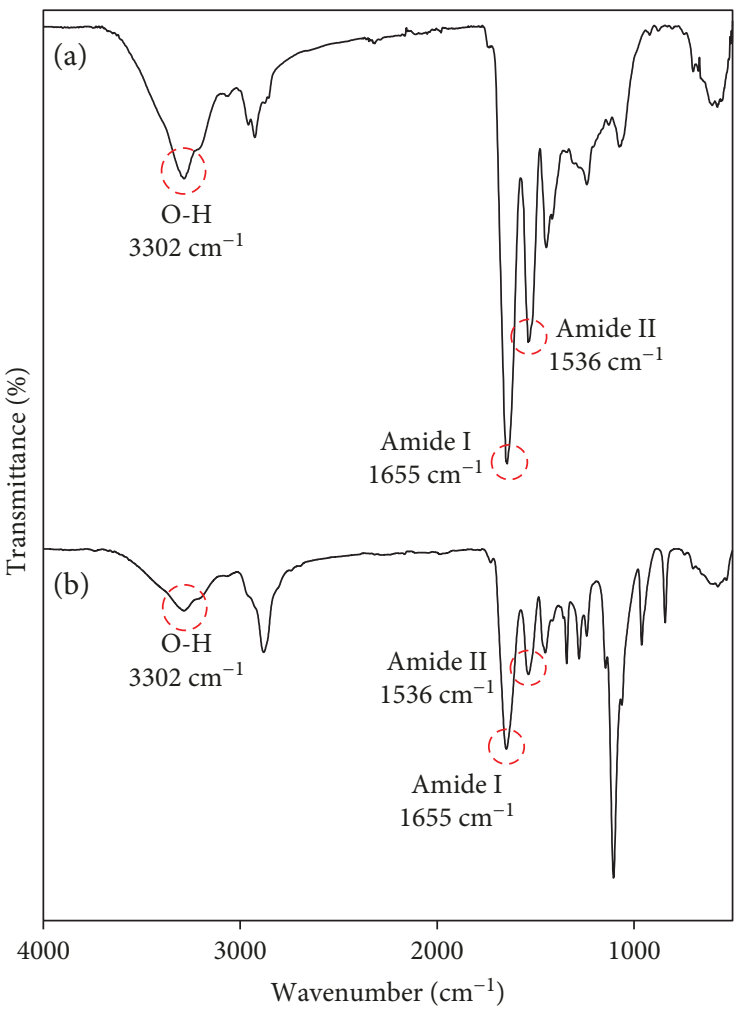

FIGURE 6: Fourier transform infrared (FTIR) spectra of (a) wheatgluten proteins soluble in ethanol (WGPSE) (gliadins, mainly) and (b) WGPSE microparticles.

that urea is a cross-linking compound. The urea present on the surface of the microparticles and the urea forming part of the polymeric matrix are the first urea that is in contact with the aqueous medium, resulting in the rapid release of the urea. These results demonstrated that WGPSE microparticles could be applied as prolonged-release fertilizer because the material presents a slow and gradual release until reaching equilibrium at $12 \mathrm{~h}$. The experiment achieves equilibrium when the urea concentration inside of the microparticles is 


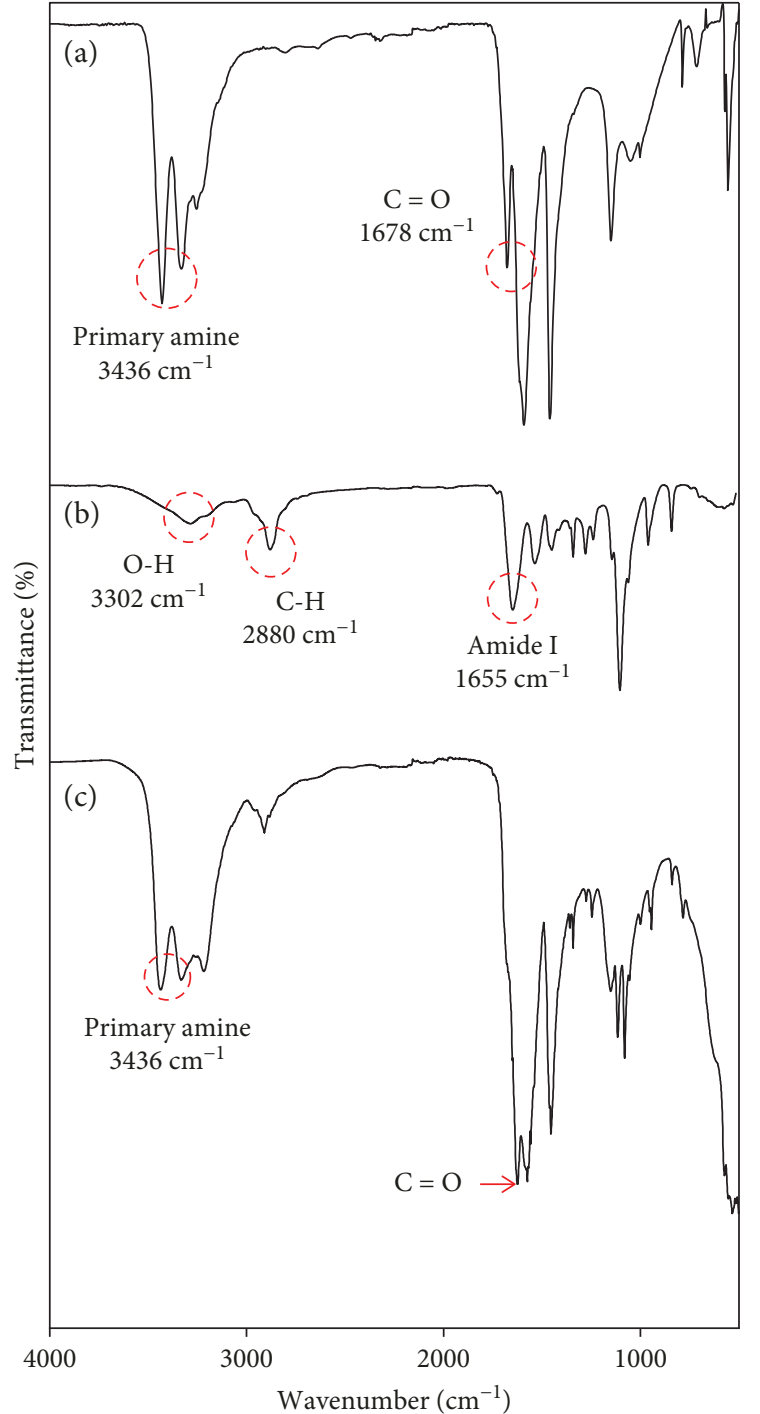

FIGURE 7: Fourier transform infrared (FTIR) spectra of (a) urea, (b) wheat-gluten proteins soluble in ethanol (WGPSE) microparticles without urea and (c) urea-loaded WGPSE microparticles.

equal to the urea concentration in the aqueous medium (outside of the microparticles), releasing $88 \%$ of the total urea loaded, which occurred when the equilibrium of diffusion is reached [33]. Castro-Enríquez et al. [14] developed urealoaded wheat-gluten membranes by means of the electrospinning technique to obtain a prolonged-release system, which achieves equilibrium at 5 hours. This result, in comparison with the results from this work, reveals an advantage of WGPSE microparticles in terms of release time. WGPSE microparticles exhibited a better release time for obtaining a prolonged-release system for potential applications in agricultural fields.

3.9. Release Kinetics of Urea. The release kinetics of urea was calculated using an empirical model developed by Ritger and Peppas. The data were modeled by (1) in its linearized form:

$$
\ln \left(\frac{M_{t}}{M_{\infty}}\right)=n \ln (t)+\ln (k)
$$

in which $M_{t}$ is the amount of urea released at time $t, M_{\infty}$ is the amount of urea released in an infinite time, $k$ is the constant release kinetics, and $n$ defines the mechanism of urea transport. On applying the empirical model of Ritger and Peppas, $k=0.63$ and $n=0.08$ were obtained. For this model, it is known that when $n \leq 0.45$, the compound release mechanism is a Fickian diffusion, when $n$ is between 0.5 and 1 , the compound release mechanism is non-Fickian, and when $n=1$, the release mechanism is anomalous (zero-order). The results obtained using this model demonstrate that kinetics release is afforded by a Fickian diffusion mechanism. The fact that the release mechanism is a Fickian diffusion provides an idea that when the WGPSE microparticles were applied, the concentration gradient exerts an effect to produce equilibrium in the system, executed by the diffusion process. The diffusion process is performed by the concentration gradient, and it takes advantage of the water solubility of urea in order to move it outside of the microparticles until an equal concentration is reached on both sides. This knowledge applied to agricultural fields comprises an advantage due to that the fields' soil is not completely wet, i.e., the WGPSE microparticles are not in constant contact with the irrigation water. This explanation reveals that this release mechanism could become a more prolonged release in the agricultural fields. Castro-Enríquez et al. [14] developed wheat-gluten membranes loaded with urea with an application in agricultural fields. The authors found that the release mechanism was carried out by relaxation of the polymeric chains and then by diffusion, obtaining a value of $k=0.07$. The difference between the values of $k$ published by Castro-Enríquez et al. [14] is attributed to the material's geometry and the release mechanism, i.e., the spheres are smaller than the membranes and do not require relaxation of the polymeric chains in comparison with that of membranes as reported by the authors. Consequently, release is increased due to the lack of the relaxation of the polymeric chains. The release process is carried out by a Fickian diffusion, which indicates that the process is performed in a single step influenced by the concentration gradient. This would explain why the release rate was much faster, in that it was not influenced by two release mechanisms, as reported for the membranes. This, in the end, would influence the prolonged release of urea through the material; however, the latter would continue to be a suitable material for its implementation as a release system.

\section{Conclusions}

Solutions of WGPSE at low concentrations demonstrate that they can be used to develop microparticles using the nanoprecipitation technique due to its shear-thickening behavior. Moreover, physicochemical characterization indicates that this material can be employed as a urea prolonged-release system. We conclude that urea-loaded WGPSE microspheres can be employed in agricultural fields as an alternative to avoid the loss of $\mathrm{N}$ and decrease the risk of the environmental 


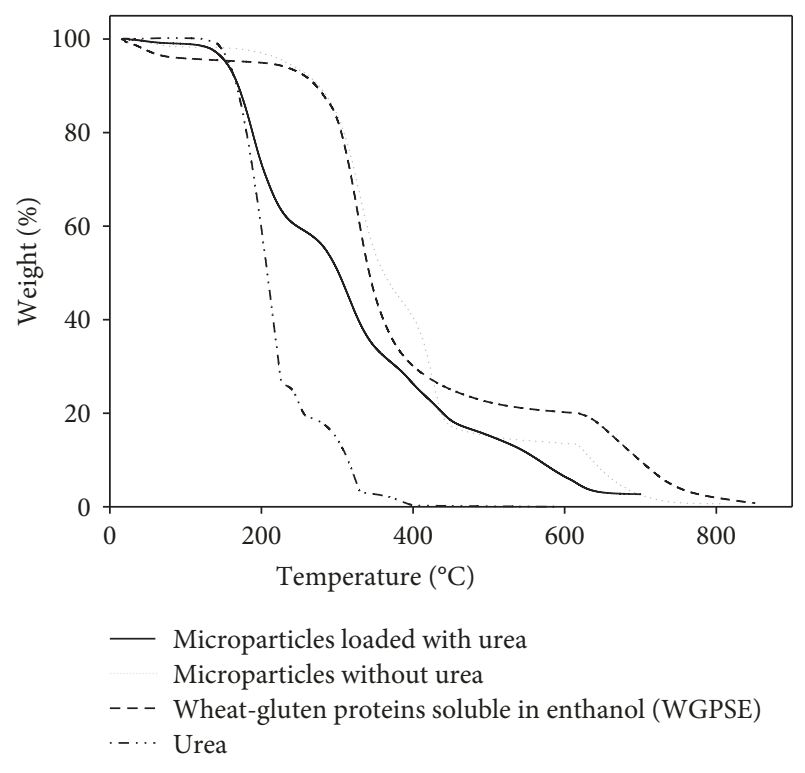

FIGURE 8: TGA curves of WGPSE microparticles loaded with urea, WGPSE microparticles without urea, WGPSE, and urea.

TABLE 4: Thermogravimetric analysis (TGA) of urea, wheat-gluten proteins soluble in ethanol (WGPSE) (gliadins, mainly), WGPSE microparticles without urea, and WGPSE microparticles loaded with urea.

\begin{tabular}{lcc}
\hline Sample & $\begin{array}{c}\text { Temperature } \\
\left({ }^{\circ} \mathrm{C}\right)\end{array}$ & $\begin{array}{c}\text { Weight } \\
\text { loss }(\%)\end{array}$ \\
\hline Urea & $145-228$ & 75 \\
& $228-477$ & 25 \\
& $25-100$ & 6 \\
Protein, soluble & $100-218$ & 8 \\
& $218-410$ & 72 \\
& $410-800$ & 12 \\
WGPSE microparticles without urea & $25-174$ & 2 \\
& $174-445$ & 80 \\
WGPSE microparticles loaded with urea & $445-800$ & 18 \\
& $25-130$ & 2 \\
& $130-800$ & 98 \\
\hline
\end{tabular}

pollution and could also aid in obtaining better quality products and greater yields of agricultural crops.

\section{Data Availability}

The data used for figures and tables to support the findings of this study are included within the supplementary information files (available here).

\section{Conflicts of Interest}

The authors declare that there are no conflicts of interest regarding the publication of this paper.

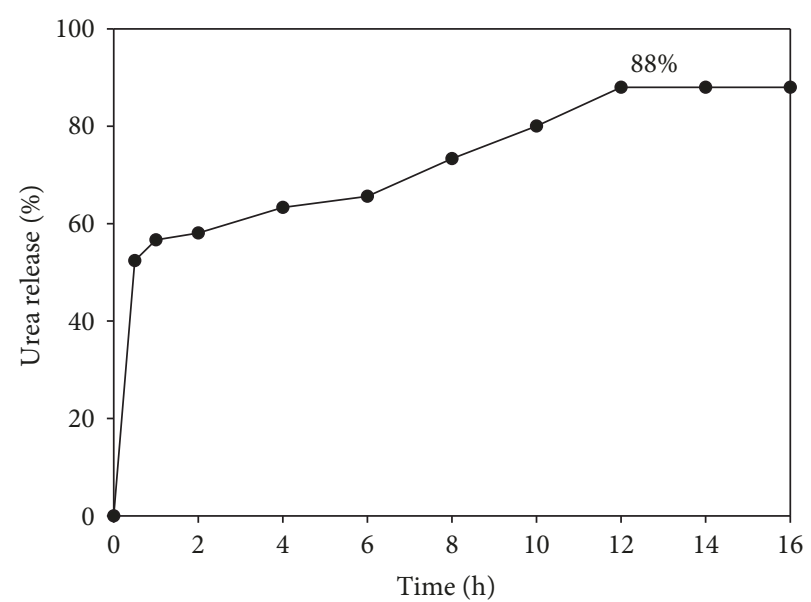

FIGURE 9: Urea release from wheat-gluten proteins soluble in ethanol (WGPSE) microparticles at $25^{\circ} \mathrm{C}$ and $\mathrm{pH} 7$.

\section{Acknowledgments}

The authors greatly appreciate the economic support of the CONACYT, through the project of basic science 178436, and the Universidad de Sonora. Carlos G. Barreras-Urbina, José Agustín Tapia-Hernández, and Daniela D. CastroEnríquez thank CONACYT for the granted scholarship.

\section{Supplementary Materials}

Supplementary 1. Data used for Figures 2 and 3. Rheological analysis.

Supplementary 2. Data used for Figures 5 and 6. Fourier transform infrared (FTIR) spectrum.

Supplementary 3. Data used for Figure 5. Fourier transform infrared (FTIR) spectrum of (A) wheat flour.

Supplementary 4. Data used for Figure 7. FTIR-loaded particles vs. urea.

Supplementary 5. Data used for Figure 7. FTIR urea.

Supplementary 6. Data used for Figure 8. TGA curves of WGPSE microparticles loaded with urea, WGPSE microparticles without urea, WGPSE, and urea.

Supplementary 7. Data used for Figure 9. Urea release from wheat-gluten proteins soluble in ethanol (WGPSE) microparticles at $25^{\circ} \mathrm{C}$ and $\mathrm{pH} 7$.

Supplementary 8. Data used for Section 3.1. Production of wheat flour and the wheat gluten Obtained.

Supplementary 9. Data used for Table 4. Thermogravimetric analysis (TGA).

\section{References}

[1] T. Kastner, M. J. I. Rivas, W. Koch, and S. Nonhebel, "Global changes in diets and the consequences for land requirements for food," Proceedings of the National Academy of Sciences of the United States of America, vol. 109, no. 18, pp. 6868-6872, 2012. 
[2] B. Azeem, K. Z. KuShaari, Z. B. Man, A. Basit, and T. H. Thanh, "Review on materials \& methods to produce controlled release coated urea fertilizer," Journal of Controlled Release, vol. 181, pp. 11-21, 2014.

[3] C. Blasco and Y. Picó, "Determining nanomaterials in food," Trends in Analytical Chemistry, vol. 30, no. 1, pp. 84-99, 2011.

[4] C. F. Chau, "An introduction to food nanotechnology," in Handbook of Food Chemistry, P. C. K. Cheung and B. M. Mehta, Eds., pp. 1087-1101, Springer, Berlin, Heidelberg, 2015.

[5] F. Shakeri, S. Shakeri, and M. Hojjatoleslami, "Preparation and characterization of carvacrol loaded polyhydroxybutyrate nanoparticles by nanoprecipitation and dialysis methods," Journal of Food Science, vol. 79, no. 4, pp. N697-N705, 2014.

[6] M. Chidambaram and K. Krishnasamy, "Modifications to the conventional nanoprecipitation technique: an approach to fabricate narrow sized polymeric nanoparticles," Advanced Pharmaceutical Bulletin, vol. 4, no. 2, pp. 205-208, 2014.

[7] C. G. Bareras-Urbina, B. Ramírez-Wong, G. A. LópezAhumada et al., "Nano- and micro-particles by nanoprecipitation: possible application in the food and agricultural industries," International Journal of Food Properties, vol. 19, no. 9, pp. 1912-1923, 2016.

[8] M. A. Robles-García, F. Rodríguez-Félix, E. Márquez-Ríos, A. Barrera-Rodríguez, J. Aguilar-Martínez, and C. L. del toro-Sánchez, "Aplicaciones biomédicas, textiles y alimentarias de nanoestructuras elaboradas por electrohilado," Biotecnia, vol. 16, no. 2, pp. 44-52, 2014.

[9] A. Roy, S. K. Singh, J. Bajpai, and A. K. Bajpai, "Controlled pesticide release from biodegradable polymers," Central European Journal of Chemistry, vol. 12, no. 4, pp. 453-469, 2014.

[10] H. Wieser, "Chemistry of gluten proteins," Food Microbiology, vol. 24, no. 2, pp. 115-119, 2007.

[11] M. Dahesh, A. Banc, A. Duri, M. H. Morel, and L. Ramos, "Polymeric assembly of gluten proteins in an aqueous ethanol solvent," Journal of Physical Chemistry B, vol. 118, no. 38, pp. 11065-11076, 2014.

[12] I. J. Joye, V. A. Nelis, and D. J. McClements, "Gliadin-based nanoparticles: stabilization by post-production polysaccharide coating," Food Hydrocolloids, vol. 43, pp. 236-242, 2015.

[13] V. Ghormade, M. V. Deshpande, and K. M. Paknikar, "Perspectives for nano-biotechnology enabled protection and nutrition of plants," Biotechnology Advances, vol. 29, no. 6, pp. 792-803, 2011.

[14] D. Castro-Enríquez, F. Rodríguez-Félix, B. Ramírez-Wong et al., "Preparation, characterization and release of urea from wheat gluten electrospun membranes," Materials, vol. 5, no. 12, pp. 2903-2916, 2012.

[15] E. Corradini, M. R. de Moura, and L. H. C. Mattoso, “A preliminary study of the incorparation of NPK fertilizer into chitosan nanoparticles," Express Polymer Letters, vol. 4, no. 8, pp. 509-515, 2010.

[16] C. Qiao, L. Liu, S. Hu, J. E. Compton, T. L. Greaver, and Q. Li, "How inhibiting nitrification affects nitrogen cycle and reduces environmental impacts of anthropogenic nitrogen input," Global Change Biology, vol. 21, no. 3, pp. 1249-1257, 2015.

[17] B. Ş. Kayserilioğlu, U. Bakir, L. Yilmaz, and N. Akkas, "Use of xylan, an agricultural by-product, in wheat gluten based biodegradable films: mechanical, solubility and water vapor transfer rate properties," Bioresource Technology, vol. 87, no. 3, pp. 239-246, 2003.
[18] N. Shukry, S. M. Fadel, F. A. Agblevor, and S. F. El-Kalyoubi, "Some physical properties of acetosolv lignins from bagasse," Journal of Applied Polymer Science, vol. 109, no. 1, pp. 434444, 2008.

[19] S. Ang, J. Kogulanathan, G. A. Morris et al., "Structure and heterogeneity of gliadin: a hydrodynamic evaluation," European Biophysics Journal, vol. 39, no. 2, pp. 255-261, 2010.

[20] S. M. Sun, Y. H. Song, and Q. Zheng, "Rheological properties of wheat gliadins in aqueous propanol," Chinese Journal of Polymer Science, vol. 31, no. 5, pp. 809-814, 2013.

[21] H. Fessi, F. Puisieux, J. P. Devissaguet, N. Ammoury, and S. Benita, "Nanocapsule formation by interfacial polymer deposition following solvent displacement," International Journal of Pharmaceutics, vol. 55, no. 1, pp. R1-R4, 1989.

[22] M. Gulfam, J. E. Kim, J. M. Lee, B. Ku, B. H. Chung, and B. G. Chung, "Anticancer drug-loaded gliadin nanoparticles induce apoptosis in breast cancer cells," Langmuir, vol. 28, no. 21, pp. 8216-8223, 2012.

[23] S. Barak, D. Mudgil, and B. S. Khatkar, "Biochemical and functional properties of wheat gliadins: a review," Critical Reviews in Food Science and Nutrition, vol. 55, no. 3, pp. 357-368, 2015.

[24] I. J. Joye, V. A. Nelis, and D. J. McClements, "Gliadin-based nanoparticles: fabrication and stability of food-grade colloidal delivery systems," Food Hydrocolloids, vol. 44, pp. 86-93, 2015.

[25] M. I. Ibba, A. M. Kiszonas, C. Guzmán, and C. F. Morris, "Definition of the low molecular weight glutenin subunit gene family members in a set of standard bread wheat (Triticum aestivum L.) varieties," Journal of Cereal Science, vol. 74, pp. 263-271, 2017.

[26] B. Lagrain, B. Goderis, K. Brijs, and J. A. Delcour, "Molecular basis of processing wheat gluten toward biobased materials," Biomacromolecules, vol. 11, no. 3, pp. 533-541, 2010.

[27] P. Fajardo, M. P. Balaguer, J. Gomez-Estaca, R. Gavara, and P. Hernandez-Muñoz, "Chemically modified gliadins as sustained release systems for lysozyme," Food Hydrocolloids, vol. 41, pp. 53-59, 2014.

[28] E. Brown and H. M. Jaeger, "Shear thickening in concentrated suspensions: phenomenology, mechanisms and relations to jamming," Reports on Progress in Physics, vol. 77, no. 4, article 046602, 2014.

[29] S. Sun, Y. Song, and Q. Zheng, "pH-induced rheological changes for semi-dilute solutions of wheat gliadins," Food Hydrocolloids, vol. 22, no. 6, pp. 1090-1096, 2008.

[30] A. Bruinink, J. Wang, and P. Wick, "Effect of particle agglomeration in nanotoxicology," Archives of Toxicology, vol. 89, no. 5, pp. 659-675, 2015.

[31] G. Davidov-Pardo, I. J. Joye, and D. J. McClements, "Encapsulation of resveratrol in biopolymer particles produced using liquid antisolvent precipitation. Part 1: preparation and characterization,” Food Hydrocolloids, vol. 45, pp. 309-316, 2015.

[32] F. Secundo and N. Guerrieri, "ATR-FT/IR study on the interactions between gliadins and dextrin and their effects on protein secondary structure," Journal of Agricultural and Food Chemistry, vol. 53, no. 5, pp. 1757-1764, 2005.

[33] R. B. Bird, “Transport phenomena," Applied Mechanics Reviews, vol. 55, no. 1, pp. R1-R4, 2002. 


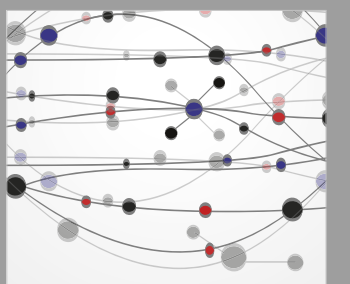

The Scientific World Journal
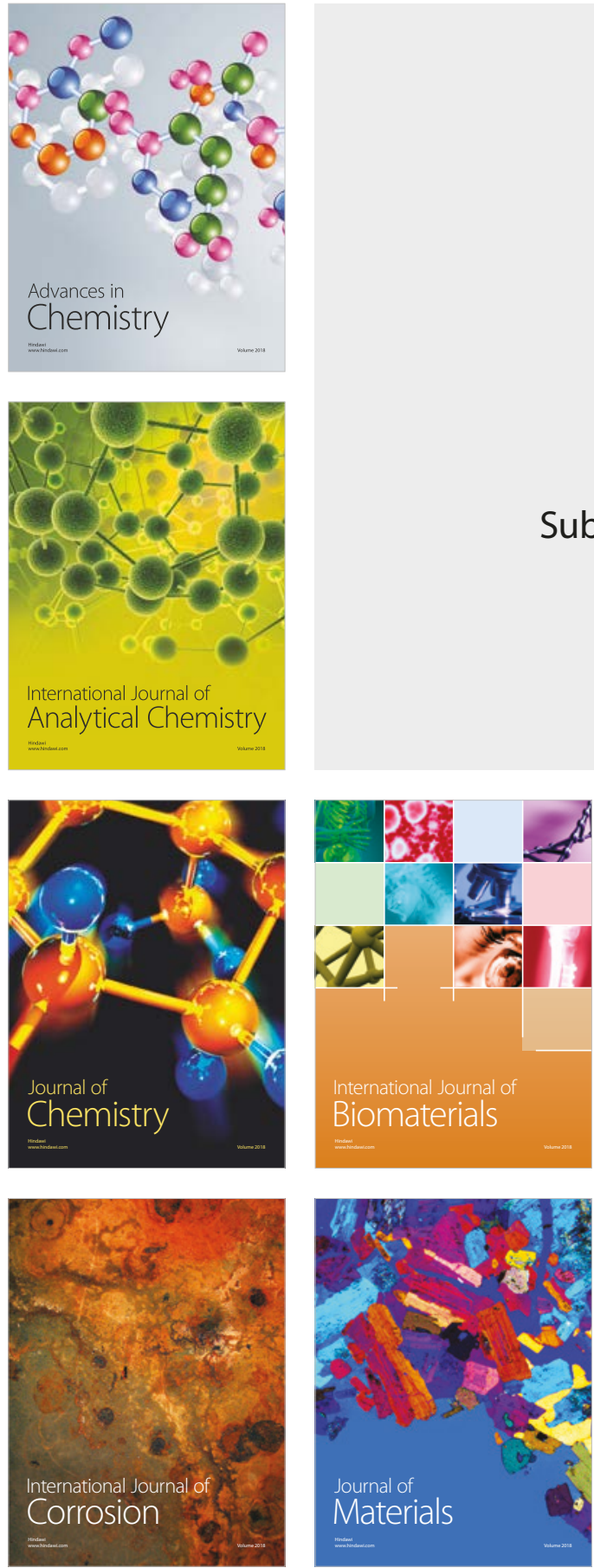

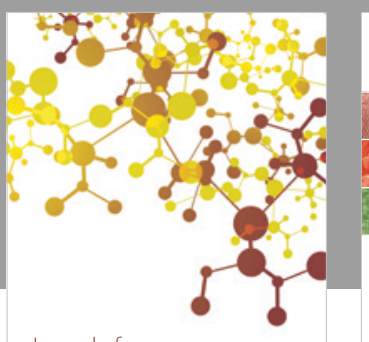

Journal of

Applied Chemistry
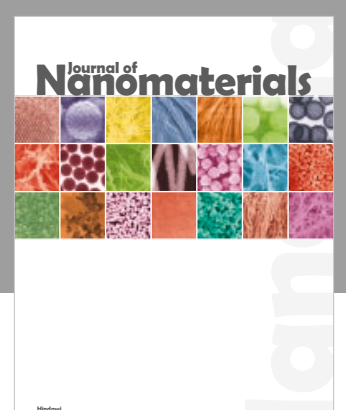

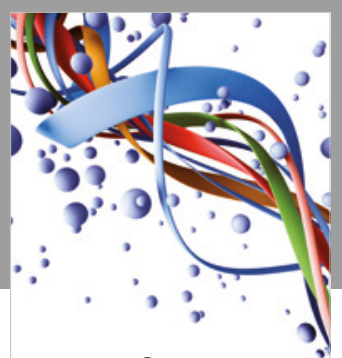

Scientifica

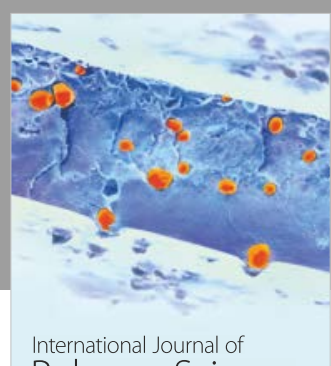

Polymer Science

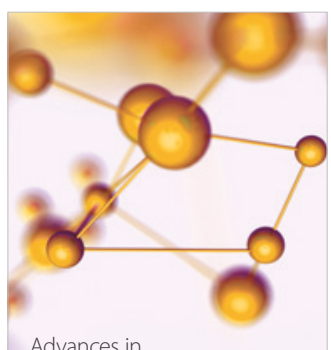

Physical Chemistry
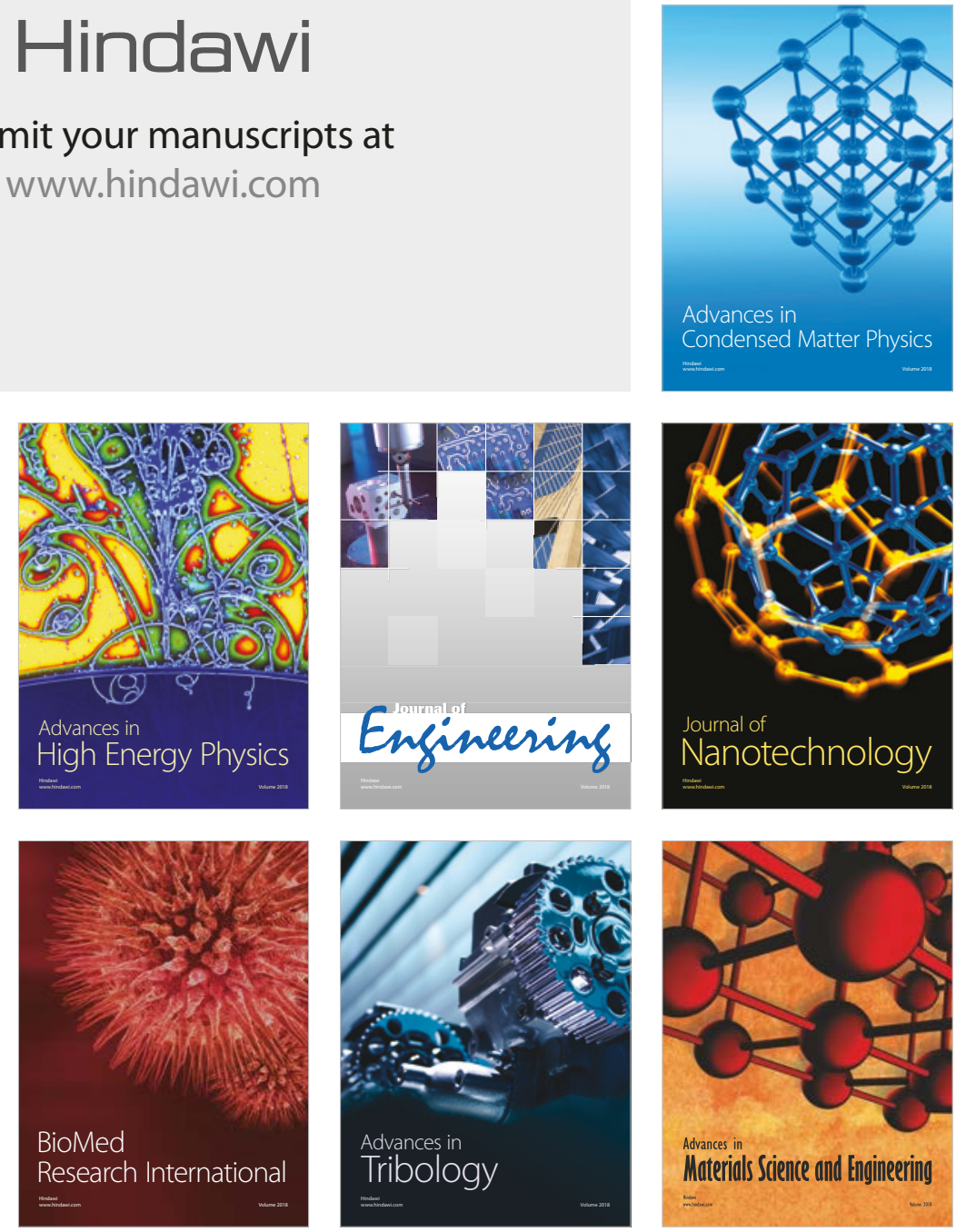